\title{
REVIEW ARTICLE OPEN The health and social implications of household air pollution and respiratory diseases
}

\author{
Suzanne M. Simkovich ${ }^{1,2}$, Dina Goodman ${ }^{1,2}$, Christian Roa ${ }^{2}$, Mary E. Crocker $\mathbb{D}^{2,3}$, Gonzalo E. Gianella ${ }^{4,5}$, Bruce J. Kirenga ${ }^{6,7}$, \\ Robert A. Wise ${ }^{1}$ and William Checkley ${ }^{1,2}$
}

\begin{abstract}
Approximately three billion individuals are exposed to household air pollution (HAP) from the burning of biomass fuels worldwide. Household air pollution is responsible for 2.9 million annual deaths and causes significant health, economic and social consequences, particularly in low- and middle-income countries. Although there is biological plausibility to draw an association between HAP exposure and respiratory diseases, existing evidence is either lacking or conflicting. We abstracted systematic reviews and meta-analyses for summaries available for common respiratory diseases in any age group and performed a literature search to complement these reviews with newly published studies. Based on the literature summarized in this review, HAP exposure has been associated with acute respiratory infections, tuberculosis, asthma, chronic obstructive pulmonary disease, pneumoconiosis, head and neck cancers, and lung cancer. No study, however, has established a causal link between HAP exposure and respiratory disease. Furthermore, few studies have controlled for tobacco smoke exposure and outdoor air pollution. More studies with consistent diagnostic criteria and exposure monitoring are needed to accurately document the association between household air pollution exposure and respiratory disease. Better environmental exposure monitoring is critical to better separate the contributions of household air pollution from that of other exposures, including ambient air pollution and tobacco smoking. Clinicians should be aware that patients with current or past HAP exposure are at increased risk for respiratory diseases or malignancies and may want to consider earlier screening in this population.
\end{abstract}

npj Primary Care Respiratory Medicine (2019)29:12 ; https://doi.org/10.1038/s41533-019-0126-x

\section{INTRODUCTION}

Respiratory diseases are responsible for a significant burden worldwide from direct healthcare costs, significant disability, premature mortality, lost productivity and social consequences. Specifically, chronic respiratory diseases are estimated to result in 92.5 million disability-adjusted life years (DALYs) lost in 2016 worldwide. ${ }^{1}$ There is limited published data on the health expenditures for respiratory disease outside of the United States (US) and the European Union (EU). ${ }^{2}$ Furthermore, available statistics grossly underestimate health costs due to widespread underdiagnoses of respiratory disease. ${ }^{2}$ For the 28 countries in the $\mathrm{EU}$, lung disease is estimated to cost $€ 379.6$ billion and results in an annual loss of 5.2 million DALYs, valued at an additional $€ 300$ billion. $^{2}$ In the US, lung diseases cost an estimated $\$ 129$ billion, with $\$ 106$ billion of this attributed to chronic obstructive

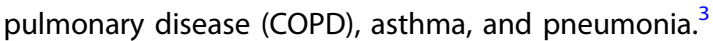

Individuals in low- and middle-income countries (LMICs) have different exposures, and consequently risk factors, for the development of respiratory diseases as compared to those in higher income countries. ${ }^{4}$ Household air pollution (HAP) exposure is an important attributable risk factor for both acute and chronic respiratory diseases in LMICs, including acute respiratory infections, $^{5-8}$ tuberculosis, $^{9,10}$ asthma, $^{5}$ COPD, $^{5,11}$ pneumoconiosis, ${ }^{12}$ head and neck cancers, ${ }^{13}$ and lung cancer. ${ }^{14,15}$ HAP exposure results from the incomplete combustion of biomass fuels (e.g., wood, dung, agricultural crop waste, and coal) during cooking and heating. Almost three billion individuals, $42.2 \%$ of the world population, continue to cook with biomass fuels due to inadequate access to clean energy. ${ }^{16}$ According to the 2016 Global Burden of Disease estimates, HAP was responsible for 2.9 million annual deaths and 81.1 million DALYs lost. ${ }^{1}$ These estimates show that $26 \%$ of HAP deaths were attributed to lower respiratory infections, 5\% to tracheal, bronchial and lung cancers, and $23 \%$ to COPD. ${ }^{17}$ Other respiratory diseases were not included in the 2016 study. ${ }^{18}$ Although HAP exposure affects all members of the household, women often have the highest risk of exposure due to their involvement in the cooking process. ${ }^{4}$ Children are also often close to their mothers and therefore can be exposed to HAP from a young age. ${ }^{4}$

Exposure to HAP not only has deleterious health effects, but also has important social consequences. Welfare and labor income losses are estimated at $\$ 1.6$ trillion and $\$ 94$ billion, respectively, due to lost productivity and poor health from HAP exposure. ${ }^{18,19}$ These losses are reflected in the poverty trap, a phenomenon where those who are in poor health, resulting from an environmental exposure such as HAP, cannot work or if they can work, their wages are lower. These individuals then cannot

\footnotetext{
${ }^{1}$ Division of Pulmonary and Critical Care, School of Medicine, Johns Hopkins University, Baltimore, MD, USA; ${ }^{2}$ Center for Global Non-Communicable Diseases, School of Medicine, Johns Hopkins University, Baltimore, MD, USA; ${ }^{3}$ Division of Pulmonary and Sleep Medicine, University of Washington, Seattle Children's Hospital, Seattle, WA, USA; ${ }^{4}$ Facultad de Medicina Alberto Hurtado, Universidad Peruana Cayetano Heredia, Lima, Peru; ${ }^{5}$ Servicio de Neumología, Unidad de Cuidados Intensivos, Clinica Ricardo Palma, Lima, Peru; ${ }^{6}$ Makerere Lung Institute, Makerere University, Kampala, Uganda and ${ }^{7}$ Pulmonology Unit, Department of Medicine, Makerere University, Mulago Hospital, Kampala, Uganda Correspondence: William Checkley (wcheckl1@jhmi.edu)

These authors contributed equally: Suzanne M. Simkovich, Dina Goodman
}

Received: 2 March 2018 Accepted: 5 March 2019

Published online: 26 April 2019 


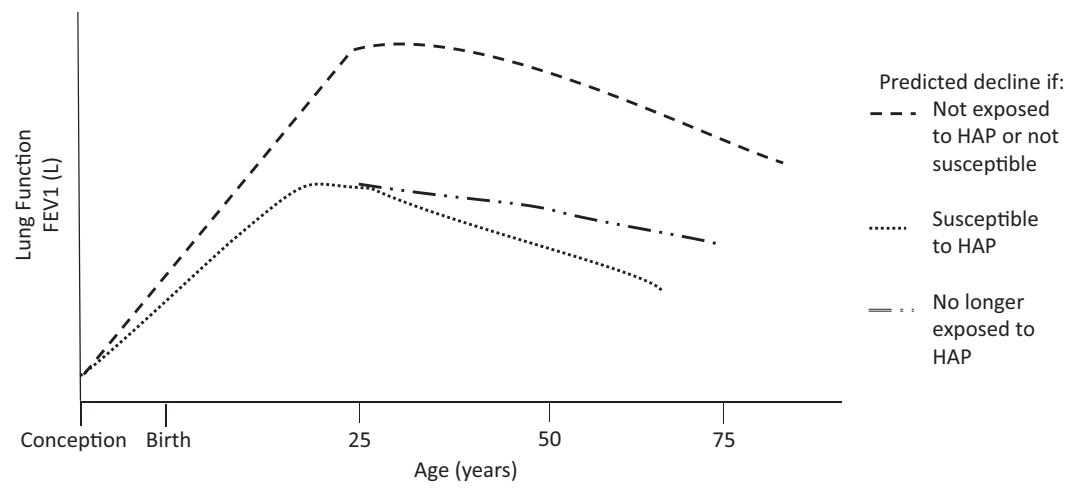

Fig. 1 This hypothesized model shows the natural history of lung function, measured as \% predicted forced expiratory value in one second (FEV1) for age. Predicted decline varies depending on the following scenarios (1) if the individual is not exposed to household air pollution (HAP) or not susceptible to respiratory illness, (2) exposed to HAP or susceptible, or (3) no longer being exposed to HAP. Those who are exposed or susceptible die from disease at a younger age, whereas those who cease exposure may reach disability but prolong life. This progression starts from conception, indicating that HAP exposure has a lifelong impact on lung function

afford goods and services that would improve their health, feeding into the vicious cycle of poverty. ${ }^{19}$ Women and children are often burdened with biomass fuel collection, ${ }^{20}$ a time consuming and potentially dangerous task as many women are subjected to violence leaving their homes to collect the fuel. ${ }^{4,19}$ This obligation forces many children to miss school and women to have fewer opportunities to engage in other economic activities. ${ }^{20}$ Other health and environmental consequences of HAP include worse ambient air pollution, deforestation, and loss of habitat for wildlife. ${ }^{21-24}$

Despite the Global Burden Disease Estimates of HAP deaths and DALYs, the relationship between HAP and respiratory diseases remains poorly characterized. One potential concern is the need to appropriately attribute HAP exposure to respiratory diseases, which requires better environmental exposure monitoring and occupational exposure screening to separate HAP from the effects of tobacco smoking, air pollution or other occupational exposures. As cigarette smoking has a been attributed to negative respiratory health outcomes, such as pneumonia, ${ }^{25}$ asthma, ${ }^{5}$ tuberculosis (TB), ${ }^{26}$ and COPD, ${ }^{27}$ several studies have also sought to evaluate the association between HAP exposure and respiratory disease. For decades, researchers have been trying to characterize the effects of HAP exposure on the lungs, using the term "hut lung" to describe the negative consequences of HAP exposure on respiratory health. ${ }^{28}$ Recently, biological mechanisms have since been further elucidated, linking noxious chemicals and particles in HAP to inflammation. For example, particulate matter, one of the more commonly studied pollutants caused by incomplete biomass combustion, has been hypothesized to stimulate an inflammatory response in airway macrophages and respiratory epithelium leading to tissue damage that can result in respiratory illnesses in susceptible individuals. $7,27,29$ HAP is thought to be particularly damaging to lungs, as fine particulate matter $\left(P_{2.5}\right)$ which is the by-product of incomplete combustion, penetrates deep into the alveoli of the lung. ${ }^{30-32}$

In utero exposure to HAP may also affect lung development and lung function across the life span. ${ }^{33}$ However, data on the natural variability of lung function over a person's lifetime are limited, and no long-term population-based studies have been conducted. ${ }^{33}$ The maximal attainment of lung function has been shown to be influenced by genetic pre-disposition, ambient air pollution, prematurity, and nutritional status. ${ }^{34}$ Those who may not reach their maximal lung function will have lower spirometric measurements throughout their lifetime. ${ }^{34}$ HAP exposure may affect maximal obtainment of lung function and subsequent lung function decline, as hypothesized in Fig. 1. Previous studies have explored the relationship between tobacco smoking and COPD in detail, $^{35}$ and have theorized that some people are more susceptible to respiratory disease. ${ }^{34}$ The rate of lung function decline is heterogeneous as some people likely experience periods of rapid decline followed by slower decline. ${ }^{34,35}$ Similar mechanisms may apply in the case of HAP exposure, where noxious particles, such as particulate matter and carbon monoxide, may affect lung development starting in utero. ${ }^{36}$

Although biological plausibility and several observational studies support an association between HAP exposure and respiratory diseases, existing literature is either lacking or conflicting, limiting our ability to make causal inferences. There are few randomized controlled trials evaluating the effect of reducing HAP exposure on respiratory health outcomes. As a result, existing reviews and meta-analyses rely primarily on caseseries and observational studies. The goal of this review is to summarize the systematic reviews and meta-analyses available for each respiratory disease then update this evidence a summary of available literature since the publication of these reviews.

\section{RESULTS}

Our primary search yielded 11 eligible systematic reviews, summarized in Table 1 . The manuscripts from the secondary search, of which 19 were included in this paper, are summarized in Table 2. Based on our scoping review, HAP exposure may be associated with ALRI, COPD, tuberculosis, pneumoconiosis, head and neck cancer, and lung cancer. All of the systematic reviews included studies that were heterogeneous in methods and results. None of the systematic reviews had an objective measure of HAP exposure, instead exposure was often based on proxies and selfreporting. Furthermore, biomass fuel type was inconsistent between each study. Many of the studies do not separate cooking and heating and some include women only or both men and women.

\section{Acute respiratory infections}

Acute respiratory infections include both upper respiratory infections (URI) and acute lower respiratory infections (ALRI). Upper respiratory infections are defined as infections of the upper respiratory structure of the aerodigestive tract, including diagnoses such as the common cold and sinusitis. ${ }^{37}$ ALRI is an acute infection of the lung from a viral or bacterial cause resulting in inflammation of the lung. ALRI is the leading cause of death in children under 5 years of age, ${ }^{38}$ and a frequent cause of hospitalization for adults in LMICs. ${ }^{2}$ Risk factors include low birth weight, malnutrition, low socioeconomic status, and smoking. ${ }^{6,8,39}$ 


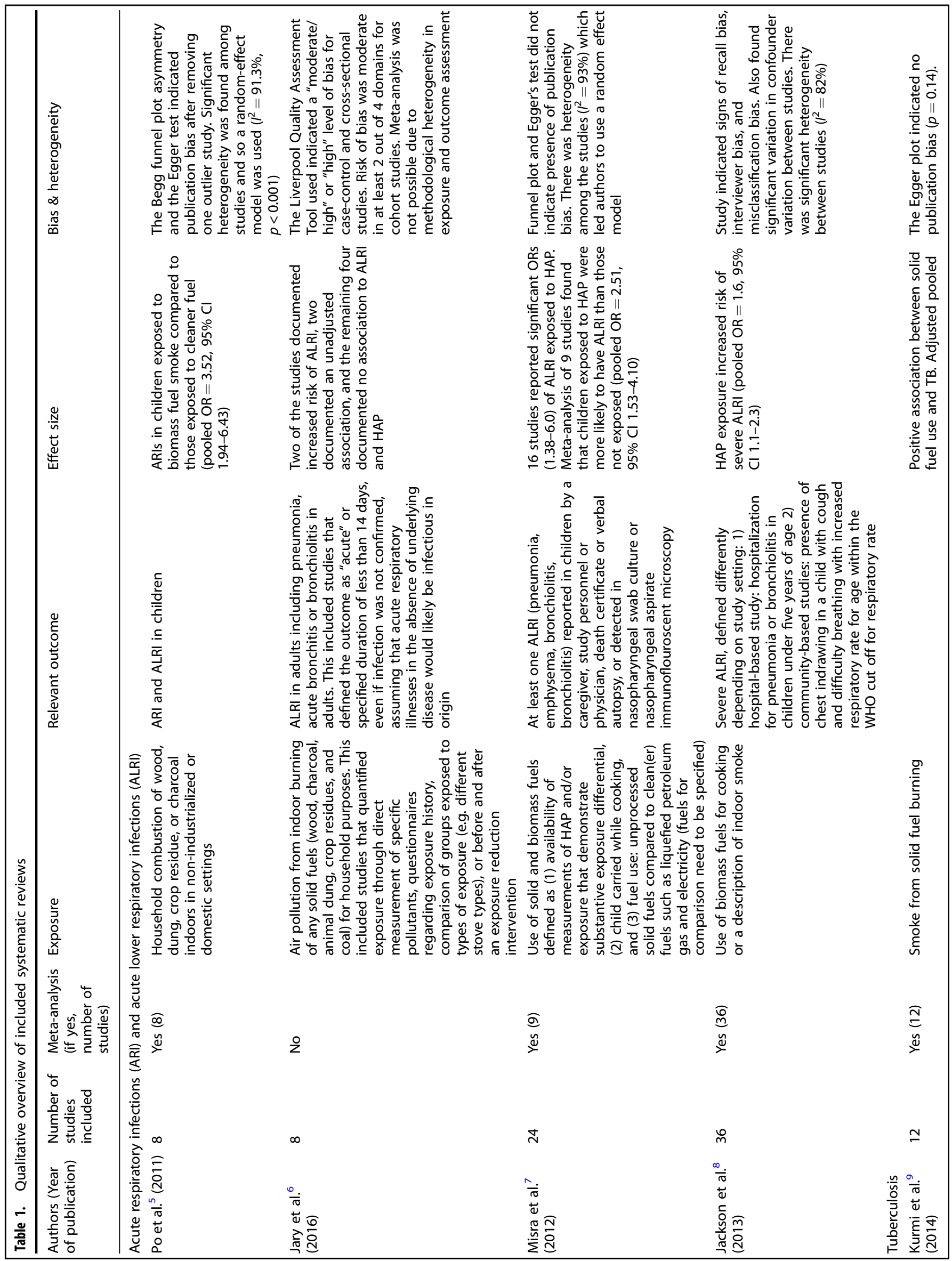




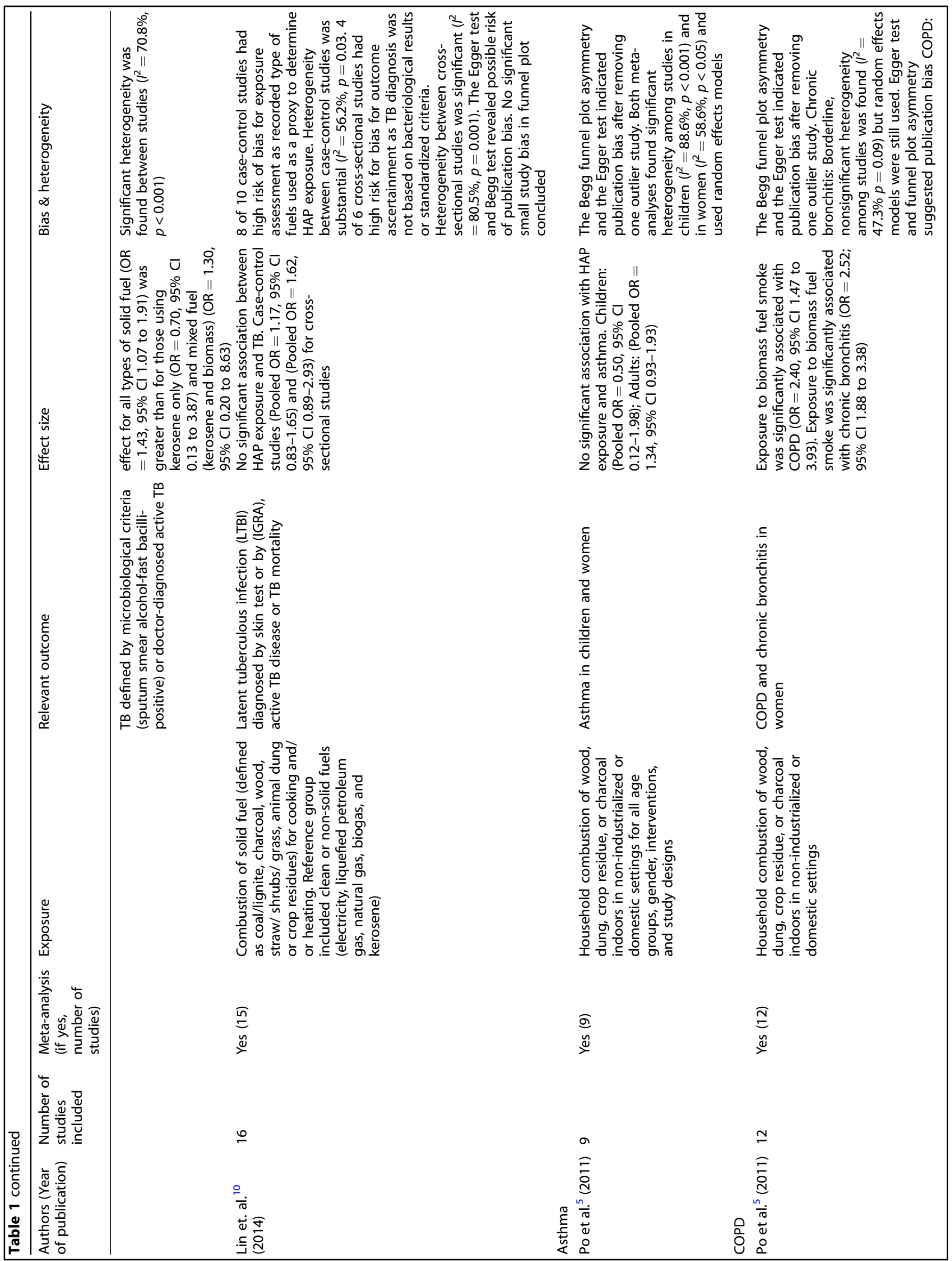




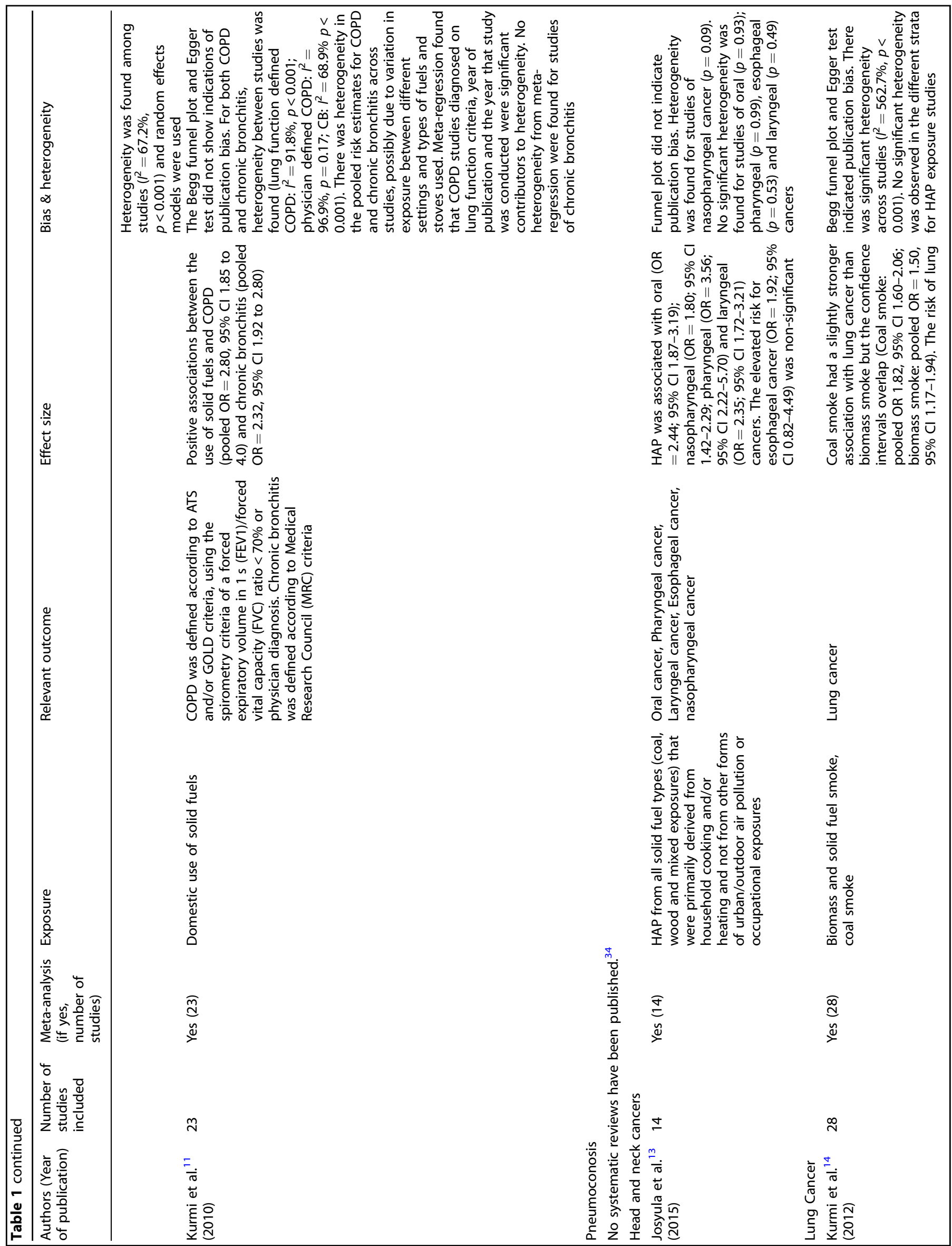


6
Existing literature has not specifically investigated the link between URI and HAP exposure, instead considering URI in combination with all other acute respiratory infections. A 2011 meta-analysis from Po et al. found that, in eight studies of acute respiratory infection, children were 3.52 times more likely to develop acute respiratory infections when exposed to HAP than those exposed to cleaner fuel or kerosene $(95 \% \mathrm{Cl} 1.93-6.43){ }^{5}$ Among adults, the evidence is less clear, and existing studies have included charcoal in the comparison group, which is not a clean fuel, ${ }^{40}$ or did not adjust for confounders. ${ }^{41,42}$

There is no clear consensus on the association between HAP exposure and ALRIs in adults. Jary et al., the only systematic review investigating this relationship, included eight eligible studies. ${ }^{6}$ Two of the studies documented an increased risk of ALRI, two documented an unadjusted association, and the remaining four documented no association. A meta-analysis was not performed as the studies were too heterogeneous in methods and results. Since its publication, no other studies have been published that further evaluate the relationship between HAP exposure and acute lower respiratory infections in adults.

The majority of studies investigating the association between HAP exposure and ALRI have focused on children under 5 years of age, as they are thought to be more susceptible to respiratory infections. ${ }^{7}$ HAP has been associated with increased risk of childhood ALRI. A systematic review by Misra et al. examined studies investigating the relationship between HAP exposure and ALRI in children under five years of age. ${ }^{7}$ Of 24 studies included for review, 16 reported significantly elevated $O R$, ranging from 1.38 to 6.0, of ALRI in those participants exposed to HAP. Nine studies were included in the meta-analysis and found that children exposed to HAP were 2.51 times more likely to have ALRI than children without exposure $(95 \% \mathrm{Cl} 1.53-4.10)$. This review did not have clear criteria for ALRI and included a spectrum of severity.

Unlike previous reviews which focused on ALRI of any severity, a meta-analysis conducted by Jackson et al. aimed to identify risk factors specific to severe ALRI, defined as hospitalization for pneumonia or bronchiolitis, in children under five. ${ }^{8}$ In the pooled analysis of five studies in LMICs, the overall odds ratio was 1.6 (95\% Cl 1.1-2.3), indicating that exposure increased the risk of severe ALRI. ${ }^{8}$

Since these two systematic reviews, three studies ${ }^{43-45}$ found that HAP exposure was associated with higher chances of developing ALRI in children. In addition, one recent randomized controlled trial in Malawi documented no association between use of a cleaner burning biomass stove and decreased pneumonia in children. ${ }^{46}$ However, this trial may have suffered from insufficient reduction of exposure. A second randomized controlled trial in Guatemala (the RESPIRE study) demonstrated the importance of misclassification of exposure in understanding the relationship between childhood pneumonia and an intervention to reduce HAP exposure. ${ }^{47}$ In this study, the intention-to-treat analysis did not show a relationship between physician-diagnosed pneumonia and use of the improved biomass stove and chimney when compared with the control ( $\mathrm{OR}=0.84,95 \% \mathrm{Cl}$ : 0.63-1.13) whereas the exposure-response analysis uncovered a significant relationship (OR $=0.82,95 \% \mathrm{Cl} 0.70-0.98)$. This emphasizes the importance of obtaining personal exposure data, as not only do exposure-response analyses aid in the integration of exposure data, but they also help to understand the threshold at which reductions in HAP exposure lead to significant health benefits. ${ }^{48}$ As shown in Fig. 2, an exposure-response curve from Burnett et al., meaningful reductions in ALRI can only be achieved if $\mathrm{PM}_{2.5}$ concentrations are reduced to $<35 \mu \mathrm{g} / \mathrm{m}^{3}$, the World Health Organization intermediate target goals for air quality in the household. ${ }^{49}$ This relationship may be applicable for all respiratory diseases discussed in this paper, but thus far has been most studied in childhood ALRI. 


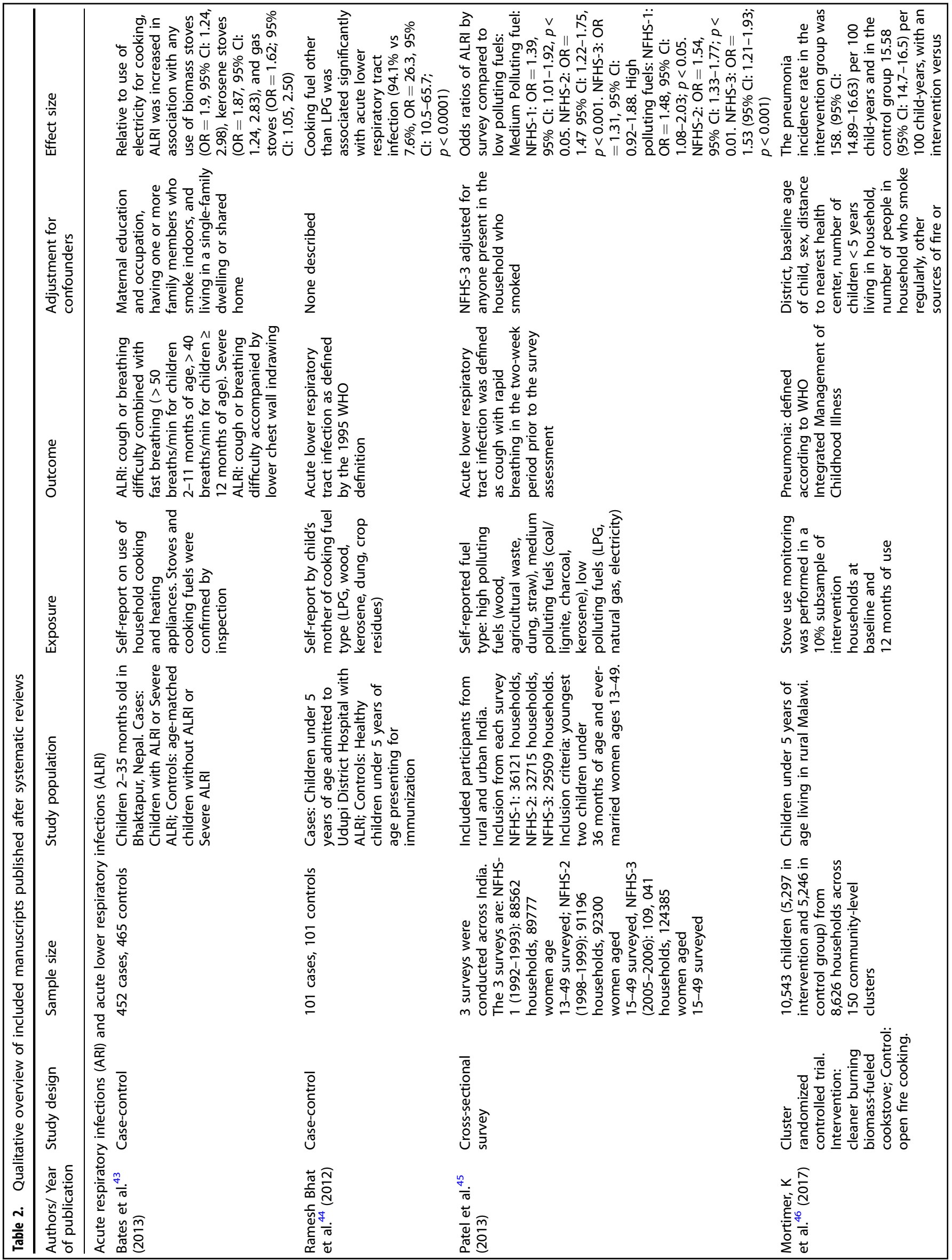




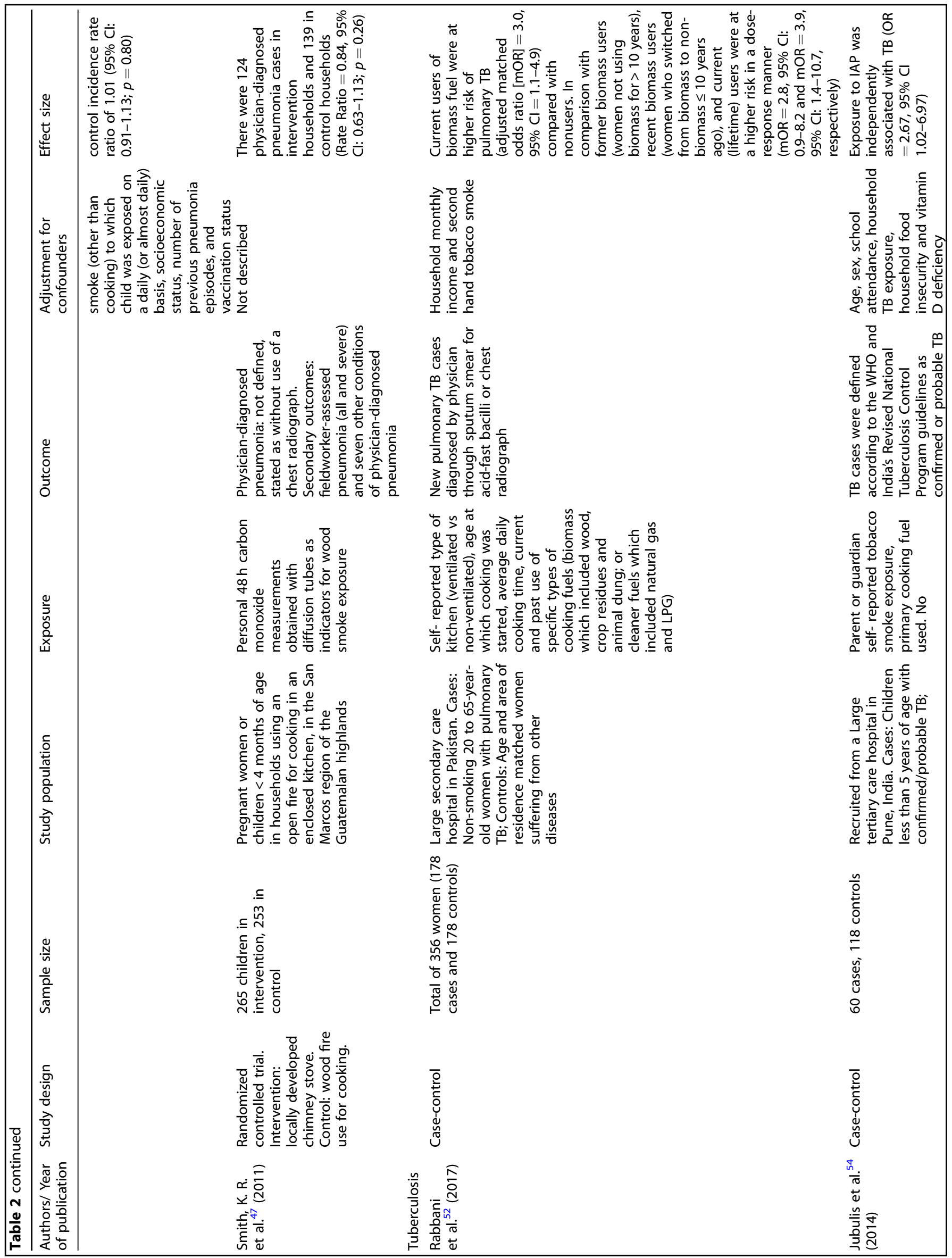




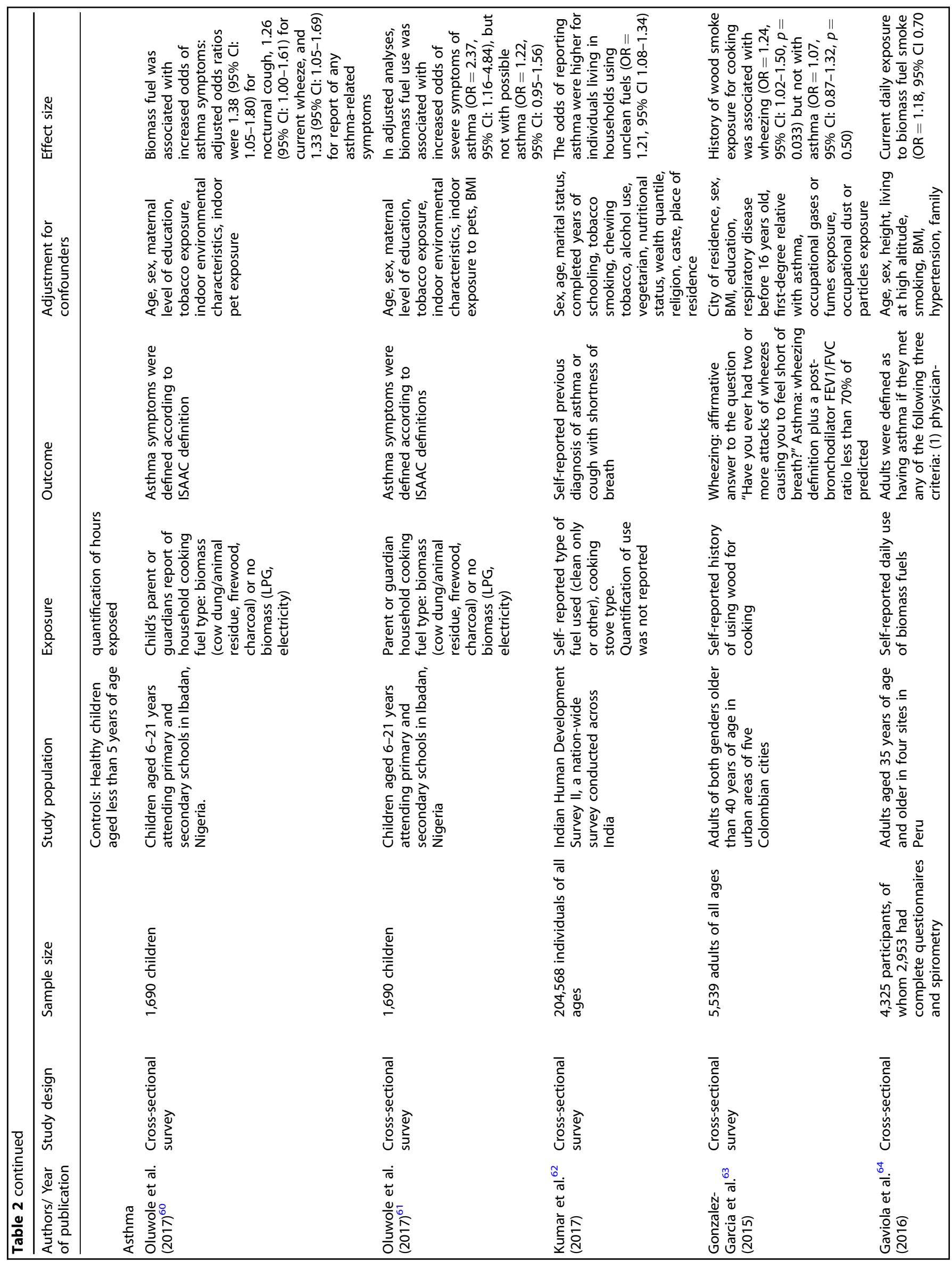




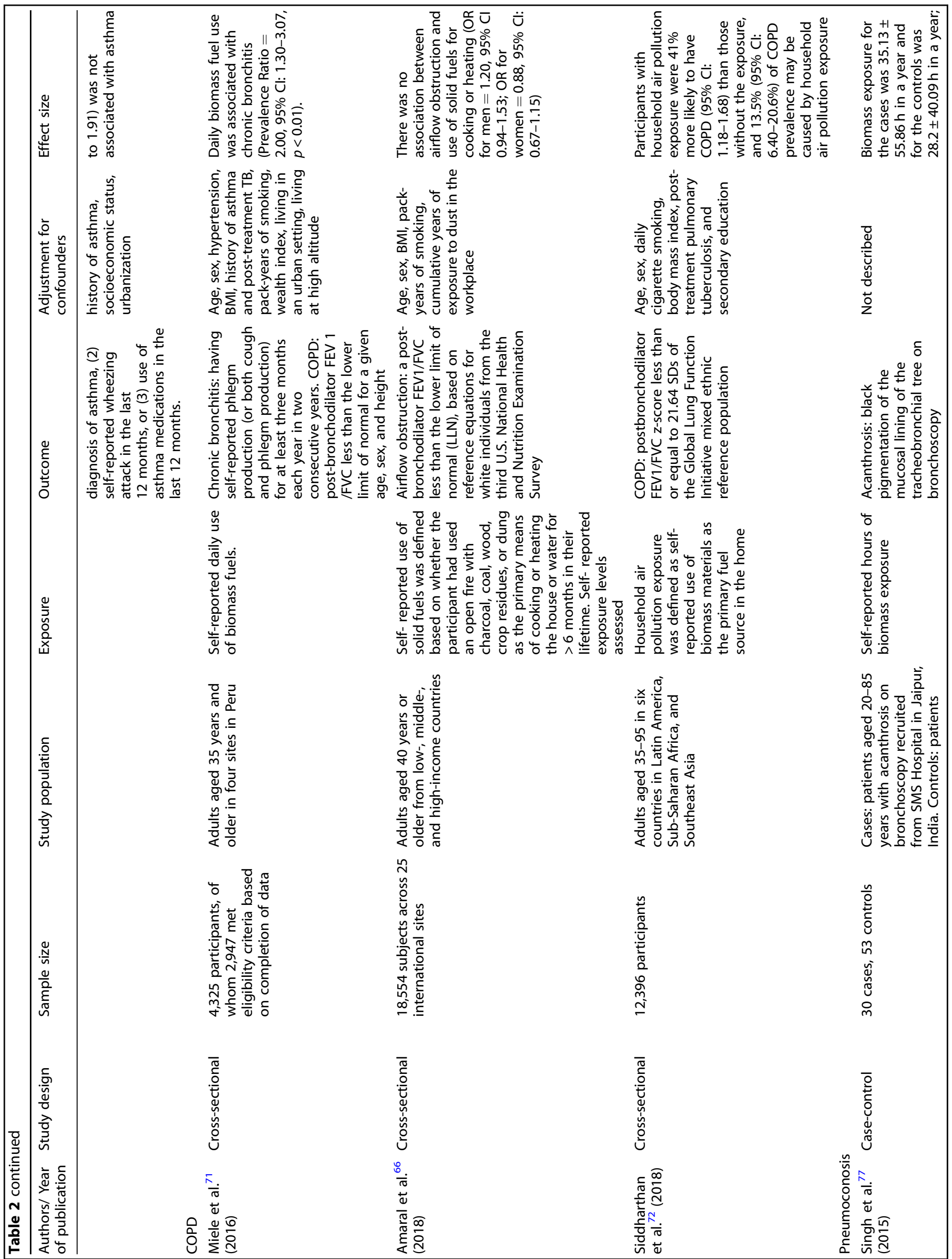




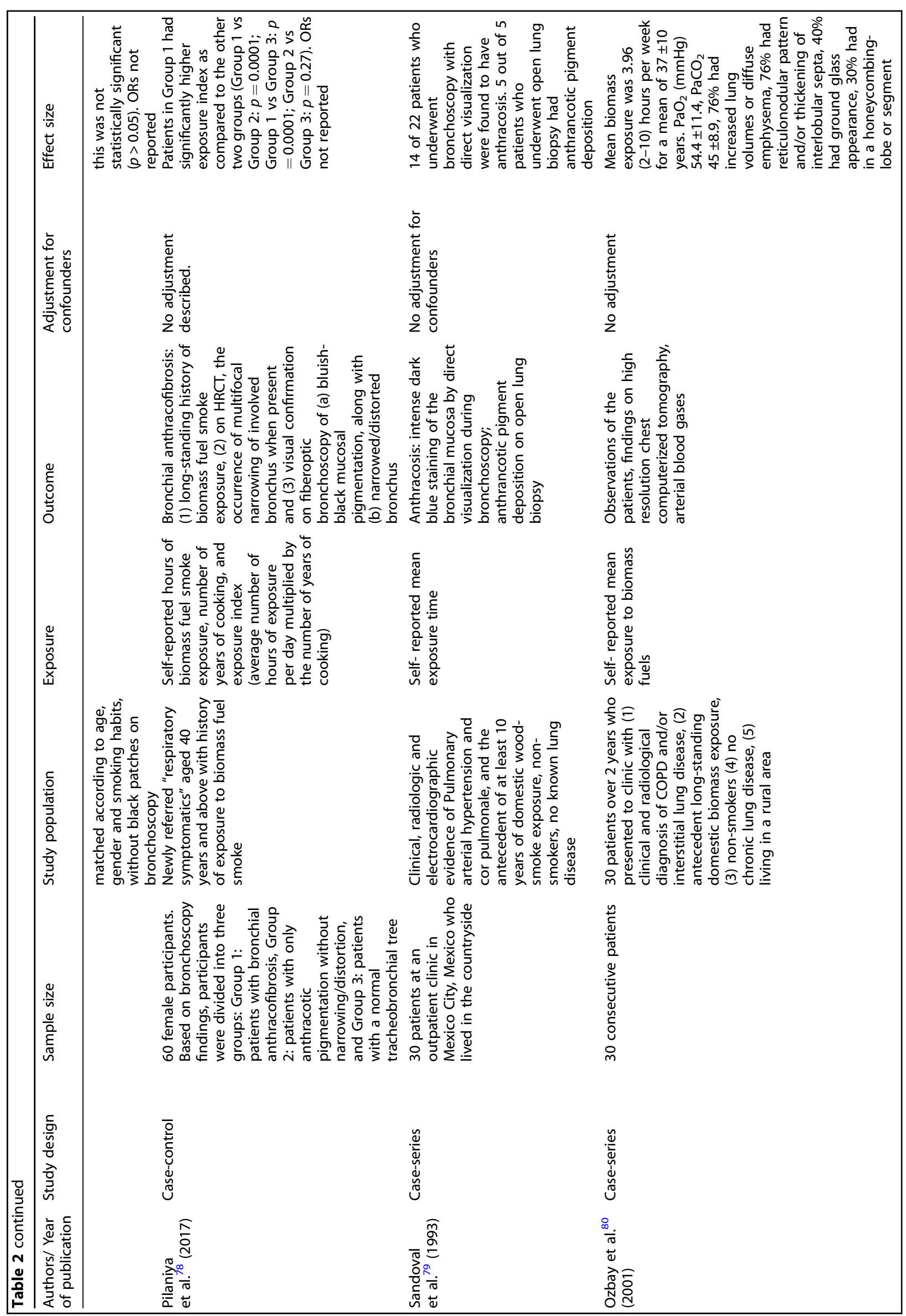




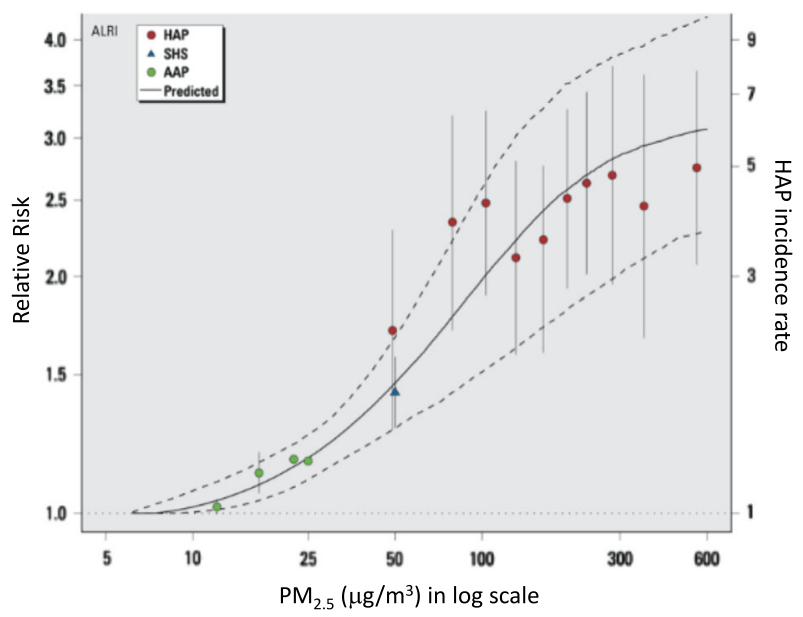

Fig. 2 The exposure-response curves here, modified from Burnett et al. 2014, show the relationship between relative risk of ALRI in infants and particulate matter $\left(\mathrm{PM}_{2.5}\right)$ exposure from household air pollution (HAP), second hand smoke (SHS), and ambient air pollution (AAP), with errors bars showing $95 \%$ confidence intervals. The solid line is the predicted values from the integrated exposure response (IER) model with dashed lines as the 95\% confidence intervals. Figure was reproduced with permission from Burnett et al. 2014

\section{Tuberculosis}

Tuberculosis (TB) is a communicable infectious disease caused by the bacillus Mycobacterium tuberculosis and is spread by inhalation of the bacteria into the lungs. This is a disease primarily affecting those in LMICs, where $95 \%$ of TB deaths occur. ${ }^{50}$ Annually 250,000 children and 1.7 million adults die from TB. ${ }^{50}$ Risk factors include HIV, living in poverty, poor nutrition, and smoking. ${ }^{26,50,51}$

There is no clear consensus on whether there is a direct link between HAP exposure and TB in adults. Given the low incidence of TB disease in single-site studies, this association has been difficult to evaluate. ${ }^{10}$ Two systematic reviews from 2014, Kurmi et al. $^{9}$ and Lin et al., ${ }^{10}$ reached opposing conclusions on the association between TB and HAP exposure. Kurmi et al. identified 12 peer-reviewed studies that evaluated active TB, controlled for smoking and reported adjusted risk estimates. ${ }^{9}$ The adjusted pooled OR was 1.43 (95\% Cl: 1.07-1.91) for all 12 studies and 1.26 (95\% Cl: 0.95-1.68) when studies with physician-diagnosed TB were removed. This analysis concluded that an individual exposed to HAP has a $43 \%$ increased risk of having active TB compared to those using clean fuels. Lin et al. identified 15 studies that included adjusted risk estimates, of which 10 were case-control studies and 5 were cross-sectional studies. ${ }^{10}$ The pooled OR from case-control studies was 1.17 (95\% Cl: $0.83-1.65)$ and $1.62(95 \% \mathrm{Cl}$ : 0.89-2.93) for the cross-sectional studies. This systematic review concluded that there was no strong evidence for a positive association between HAP exposure and TB. In fact, Lin et al. questions the conclusion drawn in Kurmi et al. since they calculated pooled OR using a fixed-effects model which may not be appropriate given the heterogeneity of the studies. Conversely, Lin et al. used the random-effects model to pool across heterogeneous studies.

Since these systematic reviews in 2014, few studies have been published evaluating the association between HAP exposure and TB. One case-control study among 178 women in rural Pakistan found a three-fold increase (OR: $3.095 \% \mathrm{Cl}$ : 1.1-4.9) in TB risk among current biomass fuel users compared to non-biomass users. $^{52}$

There is also sparse literature evaluating the relationship between HAP exposure and TB in children. Only two studies could be identified that exclusively looked at HAP exposure and reported adjusted risk estimates: Ramachandran et al. and Jublis et al. yielded ORs of $6.9(95 \% \mathrm{Cl}: 2.5-18.9)^{53}$ and $7.2(95 \% \mathrm{Cl}$ : $1.4-44.5){ }^{54}$ respectively. Both of these studies suggest that HAP exposure increases the risk of TB in children. Since that review, there have not been any significant studies published evaluating the association between HAP exposure and TB. Future populationbased studies are in progress but results have yet to be published. ${ }^{55}$

\section{Asthma}

Asthma is a non-communicable respiratory disease that is caused by chronic inflammation of the airways and results in wheezing, chest tightness, and cough. ${ }^{56}$ Asthma may develop as an allergic disorder, and a large proportion of asthma cases have sensitization to aeroallergens. ${ }^{57}$ For the purpose of population-based studies, there is no clear definition of asthma, and studies use epidemiological definitions that include self-reported symptoms of wheezing in the past 12 months, physician reported wheezing or bronchodilator responsiveness. ${ }^{56}$ In 2015, approximately 400,000 people died of asthma worldwide, though asthma is considered severely under-diagnosed. ${ }^{58}$ Many risk factors are thought to be involved in the development of asthma, however, thus far smoking and occupational allergen exposure are the most clear risk factors. ${ }^{59}$ Interestingly, asthma is more prevalent in higher income countries and more urban areas. ${ }^{56}$

There is not a clear consensus on whether there is a direct link between HAP exposure and asthma in children or adults. Po et al. performed meta-analyses of four studies on asthma in children and five studies on asthma in adults, and did not find a significant association with HAP exposure (children: $\mathrm{OR}=0.50,95 \%$ Cl $0.12-1.98$; adults: $O R=1.34,95 \% \mathrm{Cl} 0.93-1.93) .^{5}$ Since the publication of that review, the studies published do not show conclusive results on the relationship between HAP exposure and asthma. Many are contradictory, with inconsistent settings and exposure definitions. ${ }^{60-64}$

\section{Chronic obstructive pulmonary disease (COPD)}

Chronic obstructive pulmonary disease (COPD) is an adult disease characterized by irreversible airflow limitation due to a mixture of small airways disease and parenchymal destruction. ${ }^{65}$ The definition of COPD includes chronic bronchitis, defined by persistent daily phlegm for three months each year for at least 2 years, ${ }^{66}$ and emphysema, the destruction of the alveoli. ${ }^{34}$ In 2015, chronic obstructive pulmonary disease (COPD) caused 3.2 million deaths worldwide (95\% Cl 3.1-3.3 million). ${ }^{67}$ The World Health Organization ranks COPD as the fourth leading cause of mortality worldwide, $90 \%$ of which was in $\mathrm{LMICs}^{68}$. Known risk factors of COPD include cigarette smoking, ambient pollution, genetics, poor socioeconomic status, and past history of TB. ${ }^{34}$

Exposure to HAP has been shown to be associated with COPD and this has been explored in multiple systematic reviews. After the definition of COPD recently changed to encompass chronic bronchitis and emphysema, prior studies looked at each disease separately. ${ }^{34}$ Two systematic reviews published months apart found that those exposed to HAP were more likely to develop chronic bronchitis and COPD. ${ }^{5,11}$ The most recent meta-analysis, by Smith et al., yielded a pooled OR of 1.94 for COPD $(95 \% \mathrm{Cl}$ $1.62-2.33)^{69}$

Since these systematic reviews, several newer publications have investigated the association between COPD and HAP exposure. CRONICAS, a population-based study in Peru, documented that daily biomass fuel use for cooking was associated with COPD (prevalence ratio $[\mathrm{PR}]=2.22,95 \% \mathrm{Cl} 1.02-4.81)^{70}$ and chronic bronchitis $(\mathrm{PR}=2.00,95 \% \mathrm{Cl} 1.30-3.07) .{ }^{71} \mathrm{~A}$ recent publication, from the Burden of Obstructive Lung Disease Initiative (BOLD) investigators, questions previous literature as their analysis of post-bronchodilator spirometry measurements from 18,554 adults 
found no association between the use of solid fuels and airflow obstruction. ${ }^{66}$ These results, however, may be skewed since these data include high-income settings with little to no biomass fuel use. Another population-based study of 12,396 adults from 13 resource-poor settings documented that those with HAP exposure were $41 \%$ more likely to have COPD $(\mathrm{OR}=1.41,95 \% \mathrm{Cl} 1.18-1.68)$ than those without the exposure. ${ }^{72}$ This study is the first one to calculate population attributable risk factor and found that $13.5 \%$ $(6.4 \%-20.6 \%)$ of COPD prevalence may due to HAP exposure. ${ }^{72}$

\section{Pneumoconiosis}

Pneumoconiosis is an inflammatory lung disease that results in parenchymal scarring and nodularity and can eventually lead to fibrosis. ${ }^{73}$ Bronchial anthracofibrosis (BAF) is type of pneumoconiosis defined by black pigmented lesions along the bronchial mucosa with bronchial narrowing. ${ }^{74}$ This is diagnosed exclusively by bronchoscopic evaluation, therefore, limiting the diagnosis in LMICs as bronchoscopy is not widely available. ${ }^{75}$ Patients with bronchial anthracofibrosis suffer from dyspnea, cough, and hemoptysis. ${ }^{76}$ There are no systematic reviews or meta-analyses that evaluate the potential association between HAP exposure and bronchial anthracofibrosis. To attempt to shed light on this issue, Gupta et al. performed an extensive literature search to evaluate the association between HAP exposure and bronchial anthracofibrosis. ${ }^{76}$ From 17 studies and 6 case series, 1320 patients were identified with bronchoscopically confirmed BAF. The review suggested that HAP exposure might be a risk factor for bronchial anthracofibrosis, particularly in non-smoking women in rural areas. ${ }^{76}$ After that review's publication, a 2015 case series study in India found that 30 consecutive participants exposed to HAP over a 13-month period were found to have black patches on their bronchial walls. ${ }^{77}$ They were matched with controls without black pigmentation. Compared to controls, cases were less likely to be exposed to HAP, although this was not statistically significant $(\mathrm{OR}=0.57 ; 95 \% \mathrm{Cl} 0.19-1.74){ }^{77}$ Furthermore, a study in India in 2017 looked at 60 non-smoking females with respiratory symptoms and exposure to HAP. This study found that $40 \%$ of women with respiratory symptoms and exposure to HAP had bronchial anthracofibrosis diagnosed by imaging and fiberoptic bronchoscopy. ${ }^{78}$

While pneumoconioses such as bronchial anthracofibrosis can result in pulmonary fibrosis, there is no consensus that HAP exposure is associated with pneumoconiosis with higher risk of progression to fibrotic lung disease. Currently, no systematic reviews or meta-analyses have evaluated this potential association, but two case series exist. The first examined 30 Mexican rural women who had evidence of pulmonary hypertension and participants were exposed for an average of 59.1 years. ${ }^{79}$ Twenty-two patients underwent bronchoscopy and 14 had anthrancotic plaques present on visual examination. Transbronchial biopsy from 14 patients showed fibrosis. Pathology from open lung biopsies in 5 patients showed fibrosis with anthracotic deposits. $^{79}$ In another case series of 30 women who were exposed to HAP over an average of 37 years and had a diagnosis of COPD received a high resolution computed tomography which consistently showed evidence of fibrosis. Two patients had open lung biopsies of which one had pathology showing end-stage fibrosis. ${ }^{80}$

\section{Head and neck cancer}

Head and neck cancers encompass cancers of the lip, oral cavity, oropharynx, larynx, and nasopharynx and the associated structures in the regions of the head and neck. This group of malignancies is the ninth most common globally. ${ }^{74}$ In LMICs, this type of cancer is often caught in the late stages and has a high mortality rate. ${ }^{81}$ Tobacco consumption (smoked and smokeless), chewing areca nut, alcohol, and HPV infection have been associated with head and neck cancers. ${ }^{74}$.
Josyula et al. performed a meta-analysis investigating the relationship between HAP exposure and head and neck cancers. ${ }^{13}$ The results from three studies that adjusted for smoking indicated that HAP exposure is associated with a 2.56 -fold increase in the risk of oral cancer (95\% Cl 1.80-3.64). Six studies yielded a pooled OR of 1.8 (95\% Cl 1.42-2.29) for nasopharyngeal cancer, although none of the individual studies controlled for smoking. Four studies reported smoking-adjusted OR of 3.56 (95\% Cl 2.22-5.70) for pharyngeal cancer. Five studies yielded smoking-adjusted OR of 2.35 (95\% Cl 1.72-3.21) for laryngeal cancer. ${ }^{13}$ Since this review, there have not been any newly published work disputing the association of HAP and head and neck cancers.

\section{Lung cancer}

Lung cancer is the most common cause of cancer death worldwide ${ }^{82}$ with 1.59 million estimated deaths in $2012 .{ }^{83}$ Lung cancer is associated with smoking and more commonly found in high-income countries where smoking is prevalent. There is a rise in incidence of lung cancer in LMICs as tobacco smoking is increasing in popularity, particularly among men. ${ }^{83}$ Although lung cancer screening programs have been widely implemented in the US, they are less common in resource-poor settings because treatment options are not as widely available. ${ }^{84}$ Beyond smoking, known risk factors for lung cancer include environmental pollutants such as radon and asbestos, as well as chronic inflammation from pneumonia or TB. ${ }^{84}$

Lung cancer has been highly associated with HAP exposure in females. There is not a demonstrated association in males, likely due to reduced time spent cooking. ${ }^{14,15}$ In 2012, Kurmi et al. performed a systematic review and meta-analysis of 28 studies evaluating HAP exposure on development of all types of lung cancer. ${ }^{14}$ The pooled analysis found a higher likelihood of developing lung cancer in women $(\mathrm{OR}=1.81,95 \% \mathrm{Cl} 1.54-2.12)$ but not in men $(\mathrm{OR}=1.16,95 \% \mathrm{Cl}$ : $0.79-1.69) .{ }^{14}$ This analysis controlled for tobacco smoking. Among fuel types, the fuel with the highest association with lung cancer was coal (OR $=1.82,95 \%$ $\mathrm{Cl}$ 1.60-2.06). The highest OR was among women in China who use coal for cooking. This meta-analysis may underestimate the impact of HAP on lung cancer risk as the studies selected did not have clean fuel controls. Subsequent to this meta-analysis, Bruce et al. found that among trials using clean fuels as a comparison group, the OR for lung cancer was 1.21 (95\% Cl 1.05-1.39) for men and 1.95 (95\% Cl 1.16-3.27) for women. ${ }^{15}$ There have not been any subsequently published manuscripts investigating this relationship that met our inclusion criteria.

\section{DISCUSSION}

Based on the literature summarized in this review, HAP exposure is associated with ALRI, COPD, tuberculosis, pneumoconiosis, head and neck cancer, and lung cancer. However, there has not been a causal link established between HAP exposure and respiratory disease. The Bradford-Hill criteria of causation allow for assessing causal evidence relating to environmental exposures and disease. ${ }^{85}$ An assessment of these criteria in the context of HAP and respiratory diseases is described in Table $3 .^{16}$ Future studies should seek to strengthen consistency in outcome and exposure definitions, establish biological gradients through dose-response relationships, and strengthen experimental evidence through randomized controlled trials that implement interventions that adequately reduce HAP exposure.

Clinicians should be aware of the increased risk of respiratory diseases and malignancies of the aerodigestive tract in patients who are actively being exposed to HAP or have been exposed at any point in their lives including in utero exposure. When evaluating respiratory symptoms of HAP exposed patients, clinicians should keep in mind that patients may not reach their 
S.M. Simkovich et al.

Table 3. Assessment of Hill's criteria of causation about the association between HAP exposure and respiratory disease

\begin{tabular}{|c|c|}
\hline Criteria & Assessment \\
\hline Strength of association & $\begin{array}{l}\text { As outlined in this review, strong and significant associations have been documented between HAP exposure } \\
\text { and ALRI, COPD, TB, pneumoconiosis, head and neck cancer, and lung cancer. }\end{array}$ \\
\hline Consistency across populations & $\begin{array}{l}\text { Consistency and reproducibility are lacking in the evidence presented in this paper due to heterogeneity } \\
\text { between studies and inconsistent case and exposure definitions. Currently available studies are not easily } \\
\text { amenable to meta-analysis due to lack of consistent definitions or diagnostic criteria for respiratory disease, } \\
\text { instead relying on caregiver- or self-reported symptoms which lack diagnostic and etiological specificity. } \\
\text { Exposure was also inconsistently defined and often not quantifiable. }\end{array}$ \\
\hline Temporality & $\begin{array}{l}\text { Temporality has been shown through prospective cohort studies that have documented HAP exposure to } \\
\text { precede respiratory diseases. }{ }^{43,44,52,79} \mathrm{There} \text { is still a need for randomized trials to lower PM } 2.5 \text { to the World } \\
\text { Health Organization standard }\left(<35 \mu \mathrm{g} / \mathrm{m}^{3}\right) \text { and document if HAP reduction leads to an improvement in } \\
\text { respiratory outcomes. }\end{array}$ \\
\hline Biological Gradient (dose-response) & $\begin{array}{l}\text { Many studies have failed to collect longitudinal exposure data to characterize the dose-response of HAP } \\
\text { exposure to respiratory outcomes. However, evidence is available for a dose-response relationship between } \\
\text { ALRI and HAP exposure. (Fig. 2) }\end{array}$ \\
\hline $\begin{array}{l}\text { Coherence with natural history, animal } \\
\text { studies }\end{array}$ & $\begin{array}{l}\text { This scoping review has found evidence of higher risk of respiratory disease in LMICs where individuals have } \\
\text { higher exposure to biomass smoke. Animal studies have also documented the harmful effects of HAP } \\
\text { exposure. }^{92}\end{array}$ \\
\hline Experiment & $\begin{array}{l}\text { Experimental or intervention-based epidemiologic evidence for HAP exposure and respiratory disease is thus } \\
\text { far limited. Several studies and trials have been conducted with the goal to lower HAP by using more } \\
\text { efficient biomass-burning cookstoves; however, it has become clear that reductions achievable by this } \\
\text { approach fall short and fail to meet the World Health Organization intermediate target goals for air quality in } \\
\text { the household }\left(\mathrm{PM} \mathrm{M}_{2.5}<35 \mu \mathrm{g} / \mathrm{m}^{3}\right){ }^{49} \text { While it is intuitive that a switch to clean energy, such as liquefied } \\
\text { petroleum gas }(\mathrm{LPG}), \text { may prevent disease, there have been no published results from large-scale } \\
\text { randomized controlled trials investigating this hypothesis. }\end{array}$ \\
\hline Analogy & There is clear evidence from similar pollutants, such as cigarette smoke and outdoor air pollution \\
\hline
\end{tabular}

maximal lung function ${ }^{34}$ if exposed early in life and may be more susceptible to the development of chronic respiratory diseases. As ALRI is one of the leading causes of death in children under 5 years of age, ${ }^{1}$ clinicians should be diligent in rapidly evaluating these children for pneumonia to provide antibiosis as quickly as possible. Although screening for all respiratory diseases and malignancies may not be possible in LMICs, when patients immigrate to developed countries clinicians need to be aware of this prior exposure and the effects on respiratory health when considering risk factors for implementing recommended screening guidelines. For example, although a patient may not have smoked cigarettes and would not qualify for lung cancer screening based on the current screening guidelines technically, biomass exposure was not considered specifically in these guidelines and may be substituted for smoking in calculating patient risk and need for screening. ${ }^{86}$ Better designed studies with a focus on characterizing exposure-disease relationship are needed to provide stronger recommendations.

Several studies and trials have been conducted with the goal to lower HAP by using more efficient biomass-burning cookstoves; however, it has become clear that achievable reductions fall short and fail to meet the World Health Organization intermediate target goals for air quality in the household $\left(<35 \mu \mathrm{g} / \mathrm{m}^{3}\right) .{ }^{49}$ As a result, scientists and policy-makers alike agree that more efficient biomass-burning cookstoves are unlikely to result in health benefits. While there is evidence for clean energy, such as liquefied petroleum gas (LPG), to prevent disease, there have been no published results from large-scale randomized controlled trials investigating this association. However, two ongoing LPG stove trials plan to fill this gap in the literature. ${ }^{87,88}$ If these trials can document health benefits associated with switching to LPG, further economic and implementation evaluations will be needed to understand if scaling up LPG interventions would be a valuable investment.

There are some limitations to our scoping review. First, time and manpower constraints limited our capacity to perform a full systematic review of original research articles as part of our secondary search. However, our primary goal was not to conduct a systematic review but instead to summarize current existing evidence for primary care physicians which we could accomplish with the approach presented here. Second, while we selected several chronic respiratory diseases to evaluate that have been linked to tobacco smoke exposure, we may have inadvertently not included some that may also be associated with HAP exposure. Several limitations arose based on the available literature included in this review. For instance, disease definitions vary greatly limiting comparability between studies. Additionally, HAP was inconsistently measured and was rarely quantified to show an exposureresponse relationship. Many of the articles included did not consistently control for important confounders, such as tobacco smoke exposure in homes or outdoor air pollution levels. Lastly, there were varying levels of heterogeneity and publication bias among studies included in systematic reviews.

While there is a relationship between HAP exposure and many respiratory disease outcomes, better evidence in the form of randomized controlled trials reducing household air pollution are needed to strengthen this association. Further studies are needed to determine the best ways to screen for chronic respiratory diseases resulting from exposure to HAP, and identify adequate treatments, Moreover, clinicians should be aware that patients 
Table 4. Inclusion and exclusion criteria for systematic reviews

\begin{tabular}{ll}
\hline Inclusion & Exclusion \\
\hline $\begin{array}{l}\text { Exposure to household air pollution (HAP) } \\
\text { caused by biomass fuels }\end{array}$ & Non-domestic exposures \\
$\begin{array}{l}\text { Occurred in a low and middle- income } \\
\text { country }\end{array}$ & $\begin{array}{l}\text { English translation } \\
\text { unavailable }\end{array}$ \\
Systematic review of the literature and/or & $\begin{array}{l}\text { Non-peer reviewed } \\
\text { meta-analysis }\end{array}$ \\
sRISMA standards met & \\
All ages &
\end{tabular}

exposed to HAP may have a unique phenotype distinct from other environmental hazards such as tobacco smoke and occupational exposures.

\section{METHODS}

This scoping review described acute respiratory infections, tuberculosis, asthma, COPD, pneumoconiosis, head and neck cancers, and lung cancer, and how prevalence and burden of these diseases relate to HAP exposure. Respiratory diseases in this review were selected to encompass obstructive and restrictive lung disease and cancers attributed to tobacco smoke exposure. Although tobacco smoke is different than HAP cigarette smoke in chemical and particulate matter make-up, there are similarities between the two, it is a natural extension to study the same diseases for exposure to other smoke related exposures such as HAP. $^{89}$

Search strategy and study selection

We searched EMBASE, PubMed, and SCOPUS for systematic reviews and meta-analyses, reported the findings of these evaluations, and summarized the remaining literature since publication of each review. The search for systematic reviews was conducted by two informationists at the Johns Hopkins University Welch Library. We searched for common acute or chronic respiratory diseases (using the terms "acute respiratory disease" or "acute lower respiratory infection" or "pneumonia," "tuberculosis" or "TB," "asthma," "chronic obstructive pulmonary disease," "COPD", "chronic bronchitis" or "emphysema," "pneumoconiosis" or "pulmonary fibrosis," "head and neck cancer," "lung cancer"), each in combination with the terms "household air pollution," "biomass," or "indoor air pollution." From the search terms provided to the informationists, a reference list of systematic reviews was provided to the authors. Selection of reviews for inclusion was undertaken by two authors (SS and DG). The literature search for systematic reviews occurred for reviews published before September 15, 2017. Based on these criteria, 63 systematic reviews were identified and 11 were included for this manuscript. We present Inclusion and exclusion criteria for systematic reviews in Table 4.

The secondary literature search was performed for manuscripts after the publication of the chosen systematic review/s for each disease up until February 1, 2018. We searched PubMed and EMBASE for original research published subsequent to each of these reviews, using the same search terms as the primary search ("acute respiratory disease" or "acute lower respiratory infection" or "pneumonia," "tuberculosis" or "TB," "asthma," "chronic obstructive pulmonary disease," "COPD", " chronic bronchitis" or "emphysema," "pneumoconiosis" or "pulmonary fibrosis," "head and neck cancer," "lung cancer"), each in combination with the terms "household air pollution," "biomass," or "indoor air pollution." We searched each selected systematic review from the primary search in PubMed and reviewed each manuscript that cited each systematic review in PubMed Central. Hand searching was performed by examining the reference lists for relevant articles. Inclusion criteria for the secondary search of primary articles were similar: exposure to HAP caused by biomass fuels, all age, and conducted in a LMIC.

\section{Data abstraction and quality assessment}

Each systematic review was evaluated by S.S. and D.G. and the most current systematic reviews that met our criteria were selected and mutually agreed upon by both authors. Abstracted statistics for each disease were confirmed by S.S., D.G., C.R., and M.C. All systematic reviews and meta-analyses included met Preferred Reporting Items of Systematic reviews and Meta-Analysis (PRISMA) standards. ${ }^{90}$ Each paper published subsequent to the last systematic review was evaluated by the authors and met the same criteria for inclusion as the systematic reviews.

\section{DATA AVAILABILITY}

All included papers are published; no primary data are presented in this paper. As such, data sharing is not applicable to this article as no datasets were generated or analyzed during the current study.

\section{ACKNOWLEDGEMENTS}

We thank Peggy Gross and Maria Truskey, informationists at Johns Hopkins Welch Medical Library, for their assistance with the literature search. We received no payment or compensation for this review. S.S., D.G., and W.C. are supported in part by the U.S. National Institutes of Health (NIH 1UM1HL134590-01). M.C. is supported by the U.S. National Institutes of Health, Fogarty International Center (5R25TW009340) as Global Health Fellow of the University of North Carolina, Morehouse School of Medicine, Johns Hopkins University and Tulane University consortium.

\section{AUTHOR CONTRIBUTIONS}

S.S. and D.G. designed and implemented the literature search in collaboration with W. C. S.S., and D.G. performed screening and data extraction. The initial draft manuscript was written by S.S., D.G., C.R., and W.C. All authors (S.S., D.G., C.R., M.C., G.G., B.K., R.W and W.C.) provided feedback and agreed with the final version. S.S. and D.G. are cofirst authors.

\section{ADDITIONAL INFORMATION}

Competing interests: The authors declare no competing interests.

Publisher's note: Springer Nature remains neutral with regard to jurisdictional claims in published maps and institutional affiliations.

\section{REFERENCES}

1. Hay, S. I. et al. Global, regional, and national disability-adjusted life-years (DALYs) for 333 diseases and injuries and healthy life expectancy (HALE) for 195 countries and territories, 1990-2016: a systematic analysis for the Global Burden of Disease Study 2016. Lancet 390, 1260-1344 (2017).

2. Gibson, G. J., Loddenkemper, R., Sibille, Y. \& Lundback, B. The European Lung White Book: Respiratory Health and Disease in Europe. 2nd ed edn, (European Respiratory Society, 2013).

3. NHLBI. Fact Book Fiscal Year 2012. (National Institutes of Health, 2013).

4. Gall, E. T., Carter, E. M., Matt Earnest, C. \& Stephens, B. Indoor air pollution in developing countries: research and implementation needs for improvements in global public health. Am. J. Public Health 103, e67-e72 (2013).

5. Po, J. Y. T., FitzGerald, J. M. \& Carlsten, C. Respiratory disease associated with solid biomass fuel exposure in rural women and children: systematic review and metaanalysis. Thorax 66, 232-239 (2011).

6. Jary, H. et al. Household air pollution and acute lower respiratory infections in adults: a systematic review. PLOS ONE 11, e0167656 (2016).

7. Misra, P., Srivastava, R., Krishnan, A., Sreenivaas, V. \& Pandav, C. S. Indoor air pollution-related acute lower respiratory infections and low birthweight: a systematic review. J. Trop. Pediatr. 58, 457-466 (2012).

8. Jackson, S. et al. Risk factors for severe acute lower respiratory infections in children-a systematic review and meta-analysis. Croat. Med. J. 54, 110-121 (2013). 
9. Kurmi, O. P., Sadhra, C. S., Ayres, J. G. \& Sadhra, S. S. Tuberculosis risk from exposure to solid fuel smoke: a systematic review and meta-analysis. J. Epidemiol. Community Health, jech-2014-204120, https://doi.org/10.1136/jech-2014-204120 (2014).

10. Lin, H. H. et al. Indoor air pollution from solid fuel and tuberculosis: a systematic review and meta-analysis. Int. J. Tuberc. Lung. Dis. 18, 613-621 (2014).

11. Kurmi, O. P., Semple, S., Simkhada, P., Smith, W. C. S. \& Ayres, J. G. COPD and chronic bronchitis risk of indoor air pollution from solid fuel: a systematic review and meta-analysis. Thorax 65, 221-228 (2010).

12. Gupta, A. \& Shah, A. Bronchial anthracofibrosis: an emerging pulmonary disease due to biomass fuel exposure [Review article]. Int. J. Tuberc. Lung. Dis. 15, 602-612 (2011).

13. Josyula, S. et al. Household air pollution and cancers other than lung: a metaanalysis. Environ. Health 14, 24 (2015).

14. Kurmi, O. P., Arya, P. H., Lam, K.-B. H., Sorahan, T. \& Ayres, J. G. Lung cancer risk and solid fuel smoke exposure: a systematic review and meta-analysis. European Respiratory Journal 40, 1228-1237 (2012).

15. Bruce, N. et al. Does household use of biomass fuel cause lung cancer? A systematic review and evaluation of the evidence for the GBD 2010 study. Thorax 70, 433-441 (2015).

16. Bruce, N. \& Smith, K. R. WHO Indoor Air Quality Guidelines: Household Fuel Combustion-Review: Health effects of household air pollution (HAP) exposure. (2014).

17. Forouzanfar, M. H. et al. Global, regional, and national comparative risk assessment of 79 behavioural, environmental and occupational, and metabolic risks or clusters of risks, 1990-2015: a systematic analysis for the Global Burden of Disease Study 2015. Lancet 388, 1659-1724 (2016).

18. The Cost of Air Pollution: Strengthening the Economic Case for Action. (University of Washington, Seattle, Washington, 2016).

19. Duflo, E., Greenstone, M. \& Hanna, R. Indoor air pollution, health and economic well-being. S.A.P.I.EN.S 1 (2008) <http://sapiens.revues.org/130>.

20. Marc A, Jeuland \& Subhrendu K, Pattanayak Benefits and costs of improved cookstoves: assessing the implications of variability in health, forest and climate impacts. PLOS ONE 7, e30338 (2012).

21. Anenberg, S. C. et al. Cleaner cooking solutions to achieve health, climate, and economic cobenefits. Environ. Sci. Technol. 47, 3944-3952 (2013).

22. Bond, T. C., Doherty, S. J. \& Fahey, D. W. Boundin gthe role of black carbon in the climate system: a scientific assessment. J. Geophys. Res. Atmos. 118, 5380-5552 (2013).

23. Jagger, P. \& Shively, G. Land use change, fuel use and respiratory health in Uganda. Energy Policy 67, 713-726 (2014).

24. Bailis, R., Drigo, R., Ghilardi, A. \& Masera, O. The carbon footprint of traditional woodfuels. Nat. Clim. Chang. 5, 266 (2015).

25. Suzuki, M. et al. Association of environmental tobacco smoking exposure with an increased risk of hospital admissions for pneumonia in children under 5 years of age in Vietnam. Thorax 64, 484-489 (2009).

26. Gegia, M. et al. Tobacco smoking and tuberculosis treatment outcomes: a prospective cohort study in Georgia. Bull. World Health Organ 93, 390-399 (2015).

27. CapistranoS. J., van ReykD., ChenH. \& OliverB. G. Evidence of biomass smoke exposure as a causative factor for the development of COPD. Toxics. 5, 5-6 (2017).

28. Mukhopadhyay, S., Gujral, M., Abraham, J. L., Scalzetti, E. M. \& lannuzzi, M. C. A Case of Hut Lung. Chest 144, 323-327 (2013).

29. Silva, R., Oyarzun, M. \& Olloquequi, J. Pathogenic mechanisms in chronic obstructive pulmonary disease due to biomass smoke exposure. Arch. Bronconeumol. 51, 285-292 (2015).

30. Stockfelt, L. et al. Effects on airways of short-term exposure to two kinds of wood smoke in a chamber study of healthy humans. Inhal. Toxicol. 24, 47-59 (2012).

31. Donaldson, K. \& Tran, C. L. Inflammation caused by particles and fibers. Inhal. Toxicol. 14, 5-27 (2002).

32. Sood, A. ERS/ATS workshop report on respiratory health effects of household air pollution. Eur. Respir. J. 51, 4-8 (2018).

33. Kirkby, J., Bountziouka, V., Lum, S., Wade, A. \& Stocks, J. Natural variability of lung function in young healthy school children. Eur. Respir. J. 48, 411-419 (2016).

34. (GOLD), G. I. f. C. O. L. D. Global Strategy for the Diagnosis, Management and Prevention of COPD. (2017).

35. Lange, P. et al. Lung-function trajectories leading to chronic obstructive pulmonary disease. N. Engl. J. Med. 373, 111-122 (2015).

36. Stocks, J., Hislop, A. \& Sonnappa, S. Early lung development: lifelong effect on respiratory health and disease. Lancet Respir. Med. 1, 728-742 (2013).

37. Grief, S. N. Upper respiratory infections. Prim. Care 40, 757-770 (2013).

38. International Vaccine Access, C. Pneumonia \& Diarrhea Progress Report 2016: Reach Goals Through Action and Innovation. (Johns Hopkins Bloomberg School of Public Health).

39. Wonodi, C. B. et al. Evaluation of risk factors for severe pneumonia in children: the Pneumonia Etiology Research for Child Health study. Clin. Infect. Dis. 54(Suppl 2), S124-S131 (2012).
40. Taylor, E. T. \& Nakai, S. Prevalence of Acute Respiratory Infections in Women and Children in Western Sierra Leone due to Smoke from Wood and Charcoal Stoves. Int. J. Environ. Res. Public Health 9, 2252-2265 (2012).

41. Kilabuko, J. H., Matsuki, H. \& Nakai, S. Air quality and acute respiratory illness in biomass fuel using homes in Bagamoyo, Tanzania. Int. J. Environ. Res. Public Health 4, 39-44 (2007).

42. Shrestha, I. L. \& Shrestha, S. L. Indoor air pollution from biomass fuels and respiratory health of the exposed population in Nepalese households. Int. J. Occup. Environ. Health 11, 150-160 (2005).

43. Bates, M. N. et al. Acute lower respiratory infection in childhood and household fuel use in Bhaktapur, Nepal. Environ. Health Perspect. 121, 637-642 (2013).

44. Ramesh Bhat, Y., Manjunath, N., Sanjay, D. \& Dhanya, Y. Association of indoor air pollution with acute lower respiratory tract infections in children under 5 years of age. Paediatr. Int. Child Health 32, 132-135 (2012).

45. Patel, A. B. et al. Childhood illness in households using biomass fuels in India: secondary data analysis of nationally representative national family health surveys. Int. J. Occup. Environ. Health 19, 35-42 (2013).

46. Mortimer, K. et al. A cleaner burning biomass-fuelled cookstove intervention to prevent pneumonia in children under 5 years old in rural Malawi (the Cooking and Pneumonia Study): a cluster randomised controlled trial. Lancet 2017, 167-175 (2017).

47. Smith, K. R. et al. Effect of reduction in household air pollution on childhood pneumonia in Guatemala (RESPIRE): a randomised controlled trial. Lancet 378, 1717-1726 (2011).

48. Burnett, R. T. et al. An integrated risk function for estimating the global burden of disease attributable to ambient fine particulate matter exposure. Environ. Health Perspect. 122, 397-403 (2014).

49. Krzyzanowski, M. \& Cohen, A. Update of WHO air quality guidelines. Air Quality, Atmosphere \& Health 1, 7-13 (2008).

50. Organization, W. H. Global Tuberculosis Report 2017. (Geneva, 2017).

51. Davies, P. D. et al. Smoking and tuberculosis: the epidemiological association and immunopathogenesis. Trans. R. Soc. Trop. Med. Hyg. 100, 291-298 (2006).

52. Rabbani, U., Sahito, A., Nafees, A. A., Kazi, A. \& Fatmi, Z. Pulmonary tuberculosis is associated with biomass fuel use among rural women in Pakistan: an age- and residence-matched case-control study. Asia Pac. J. Public Health 29, 211-218 (2017).

53. Ramachandran, R. I. P. S., Anish, T. S., Nair, S., Lawrence, T. \& Rajasi, R. S.Determinants of childhood tuberculosis - a case control study among children registered under revised national tuberculosis control programme in a district of South India. Indian J. Tuberc. 58, 204-207 (2011).

54. Jubulis, J. et al. Modifiable risk factors associated with tuberculosis disease in children in Pune, India. Int. J. Tuberc. Lung. Dis. 18, 198-204 (2014).

55. Jafta, N., Barregard, L., Jeena, P. M. \& Naidoo, R. N. Indoor air quality of low and middle income urban households in Durban, South Africa. Environ. Res. 156, 47-56 (2017).

56. Asher, I. \& Pearce, N. Global burden of asthma among children. Int. J. Tuberc. Lung. Dis. 18, 1269-1278 (2014).

57. Pearce, N., Pekkanen, J. \& Beasley, R. How much asthma is really attributable to atopy? Thorax 54, 268 (1999).

58. Ellwood, P. The Global Asthma Network rationale and methods for Phase I global surveillance: prevalence, severity, management and risk factors. Eur. Respir. J. 49, 1-2 (2017).

59. Beasley, R., Semprini, A. \& Mitchell, E. A. Risk factors for asthma: is prevention possible? Lancet 386, 1075-1085 (2015).

60. Oluwole, O., Arinola, G. O., Huo, D. \& Olopade, C. O. Biomass fuel exposure and asthma symptoms among rural school children in Nigeria. J. Asthma. 54, 347-356 (2017).

61. Oluwole, O., Arinola, G. O., Huo, D. \& Olopade, C. O. Household biomass fuel use, asthma symptoms severity, and asthma underdiagnosis in rural schoolchildren in Nigeria: a cross-sectional observational study. BMC Pulm. Med. 17, 3 (2017).

62. Kumar, P. \& Ram, U. Patterns, factors associated and morbidity burden of asthma in India. PLOS ONE 12, e0185938 (2017).

63. Gonzalez-Garcia, M., Caballero, A., Jaramillo, C., Maldonado, D. \& Torres-Duque, C. A. Prevalence, risk factors and underdiagnosis of asthma and wheezing in adults 40 years and older: A population-based study. J. Asthma. 52, 823-830 (2015).

64. Gaviola, C. et al. Urbanisation but not biomass fuel smoke exposure is associated with asthma prevalence in four resource-limited settings. Thorax 71, 154-160 (2016).

65. Angelis, N. et al. Airway inflammation in chronic obstructive pulmonary disease. J. Thorac. Dis. 6(Suppl 1), S167-S172 (2014).

66. Amaral, A. F. S. Airflow Obstruction and Use of Solid Fuels for Cooking or Heating: BOLD Results. Am. J. Respir. Crit. Care. Med. 595-610 (2017).

67. Collaborators, G. C. R. D. Global, regional, and national deaths, prevalence, disability-adjusted life years, and years lived with disability for chronic obstructive pulmonary disease and asthma, 1990-2015: a systematic analysis for the Global Burden of Disease Study 2015. Lancet Respir. Med. 5, 691-706 (2017). 
68. Mathers, C. The global burden of disease: 2004 update. (World Health Organization, 2008).

69. Smith, K. R. et al. Millions Dead: How Do We Know and What Does It Mean? Methods Used in the Comparative Risk Assessment of Household Air Pollution. Annu. Rev. Public Health 35, 185-206 (2014).

70. Jaganath, D. et al. Prevalence of chronic obstructive pulmonary disease and variation in risk factors across four geographically diverse resource-limited settings in Peru. Respir. Res. 16, 40 (2015).

71. Miele, C. H. et al. Urbanization and daily exposure to biomass fuel smoke both contribute to chronic bronchitis risk in a population with low prevalence of daily tobacco smoking. COPD, 1-10 (2015).

72. Siddharthan, T. et al. Association between household air pollution exposure and chronic obstructive pulmonary disease outcomes in 13 low- and middle-income country settings. Am. J. Respir. Crit. Care. Med. 197, 611-620 (2018).

73. Cullinan, P. \& Reid, P. Pneumoconiosis. Prim. Care. Respir. J. 22, 249-252 (2013).

74. Gupta, B., Johnson, N. W. \& Kumar, N. Global epidemiology of head and neck cancers: a continuing challenge. Oncology 91, 13-23 (2016).

75. Kunal, S., Pilaniya, V. \& Shah, A. Bronchial anthracofibrosis with interstitial lung disease: an association yet to be highlighted. BMJ. Case Rep. 2016, pii: bcr2015213940 (2016).

76. Gupta, A. \& Shah, A. Bronchial anthracofibrosis: an emerging pulmonary disease due to biomass fuel exposure. Int. J. Tuberc. Lung. Dis. 15, 602-612 (2011).

77. Singh, V. et al. Clinico-radiological profile and risk factors in patients with anthracosis. Lung India 32, 102-106 (2015).

78. Pilaniya, V., Kunal, S. \& Shah, A. Occurrence of bronchial anthracofibrosis in respiratory symptomatics with exposure to biomass fuel smoke. Adv. Respir. Med. 85, 127-135 (2017)

79. Sandoval, J. et al. Pulmonary arterial hypertension and cor pulmonale associated with chronic domestic woodsmoke inhalation. Chest 103, 12-20 (1993).

80. Ozbay, B., Uzun, K., Arslan, H. \& Zehir, I. Functional and radiological impairment in women highly exposed to indoor biomass fuels. Respirology 6, 255-258 (2001).

81. Bilal, S., Doss, J. G., Cella, D. \& Rogers, S. N. Quality of life associated factors in head and neck cancer patients in a developing country using the FACT-H\&N. J. Craniomaxillofac. Surg.43, 274-280 (2015).

82. Fitzmaurice, C. et al. The Global Burden of Cancer 2013. JAMA Oncol. 1, 505-527 (2015).

83. Islami, F., Torre, L. A. \& Jemal, A. Global trends of lung cancer mortality and smoking prevalence. Transl. Lung Cancer Res. 4, 327-338 (2015).
84. McIntyre, A. \& Ganti, A. K. Lung cancer-A global perspective. J. Surg. Oncol. 115 550-554 (2017).

85. Hill, A. B. The environment and disease: association or causation? Proc. R. Soc. Med. 58, 295-300 (1965).

86. Tammemagi, M. C. et al. Selection criteria for lung-cancer screening. N. Engl. J. Med. 368, 728-736 (2013).

87. Fandiño-Del-Rio, M. et al. Effects of a liquefied petroleum gas stove intervention on pollutant exposure and adult cardiopulmonary outcomes (CHAP): study protocol for a randomized controlled trial. Trials 18, 518 (2017).

88. Household Air Pollution and Health: A Multi-country LPG Intervention Trial, https:// clinicaltrials.gov/ct2/show/NCT02944682 (2018).

89. Mehra, D., Geraghty, P. M., Hardigan, A. A. \& Foronjy, R. A comparison of the inflammatory and proteolytic effects of dung biomass and cigarette smoke exposure in the lung. PLOS ONE 7, e52889 (2012).

90. Moher, D., Liberati, A., Tetzlaff, J., Altman, D. G. \& Group, P. Preferred reporting items for systematic reviews and meta-analyses: the PRISMA statement. Int. J. Surg. 8, 336-341 (2010).

91. Howick, J., Glasziou, P. \& Aronson, J. K. The evolution of evidence hierarchies: what can Bradford Hill's 'guidelines for causation' contribute? J. R. Soc. Med. 102, 186-194 (2009).

92. Household use of solid fuels and high-temperature frying. IARC Monogr. Eval. Carcinog. Risks Hum. 95, 1-430 (2010).

(i) Open Access This article is licensed under a Creative Commons Attribution 4.0 International License, which permits use, sharing, adaptation, distribution and reproduction in any medium or format, as long as you give appropriate credit to the original author(s) and the source, provide a link to the Creative Commons license, and indicate if changes were made. The images or other third party material in this article are included in the article's Creative Commons license, unless indicated otherwise in a credit line to the material. If material is not included in the article's Creative Commons license and your intended use is not permitted by statutory regulation or exceeds the permitted use, you will need to obtain permission directly from the copyright holder. To view a copy of this license, visit http://creativecommons. org/licenses/by/4.0/.

(c) The Author(s) 2019 